\title{
Predicting Financial Crisis by Examining Risk-Return Relationship
}

\author{
Sanjay Sehgal ${ }^{1}$, Asheesh Pandey² \\ ${ }^{1}$ Department of Financial Studies, University of Delhi, South Campus, New Delhi, India \\ ${ }^{2}$ Fortune Institute of International Business, New Delhi, India \\ Email: sanjayfin15@gmail.com, asheeshpandey@rediffm ail.com
}

How to cite this paper: Sehgal, S. and Pandey, A. (2018) Predicting Financial Crisis by Examining Risk-Return Relationship. Theoretical Economics Letters, 8, 48-71.

https://doi.org/10.4236/tel.2018.81003

Received: September 29, 2017

Accepted: January 7, 2018

Published: January 10, 2018

Copyright ( 92018 by authors and Scientific Research Publishing Inc. This work is licensed under the Creative Commons Attribution International License (CC BY 4.0).

http://creativecommons.org/licenses/by/4.0/

cc) (7) Open Access

\begin{abstract}
We test the risk-return relationship in and around the global financial crisis for three market groups namely developed, emerging and frontier markets, from June 2005 to June 2016. Four risk proxies are used viz. Standard Deviation, Semi Deviation, Beta and Downside Beta. We find that the global financial crisis had a de-coupling effect as the return associations between global financial markets declined for the post crisis period. We also observe high positive correlations between alternative risk measures implying that asset pricing tests shall be robust to choice of risk measure. Next, we find that the risk-return relationship is absent in the pre-crisis period while it is significantly negative in the post crisis period using standard deviation based measures. Thus, the breaking down of risk-return relationship may be an important predictor of any forthcoming crisis. Further, global capital markets seem to behave like distressed economies in the post crisis period and, hence, exhibit option like behavior. We re-verify our hypothesis by using data in and around the Asian Crisis Period and confirm the absence of risk-return relationship prior to the crisis period. The study contributes to capital market literature with special emphasis on financial crisis.
\end{abstract}

\section{Keywords}

Risk-Return Relationship, Cost of Equity, Financial Crisis, Risk Measures, CAPM

\section{Introduction}

The relationship between risk and return has been focus of research in contemporary finance literature. The initial theoretical framework for risk-return relationship was provided by Sharpe [1], Lintner [2] and Mossin [3] in which they 
established a positive linear relationship between risk and return through Capital Asset Pricing Model (CAPM). A number of empirical studies have been conducted since then to test risk-return relationship. The results of such studies are mixed. Few of them find a positive relationship between risk and return while others observe that such a relationship is negative.

The understanding of risk-return relationship is necessary to build valuation models. There are predominantly two approaches to business valuation viz. Discounted Cashflow Model (DCF) and Contingent Claims Approach. DCF is the principle fundamentals based technique for valuing assets using three fundamental drivers namely cashflows, growth and risk. Theoretically, equity value is positively related to cash flows and growth and negatively related to cost of capital which is the direct function for risk. Thus, while theoretically risk-return relationship is positive, risk and valuation relationship is negative. In Contingent Claims Approach, equity is treated as a call option with value of asset as Spot Price and debt as an exercise price. If the asset value is greater than the debt value, then it is in the money, and else it is out of the money call option. Contingent Claims Approach is more relevant for distressed firms whose leverage levels are high and cash flows are low or negative. Just like companies are distressed at micro level, economies can also be distressed at macro level. In such cases, the total GDP of those economies proxies for spot price and debt level of these economies becomes exercise price. In crisis periods, GDP of economies become stressed while their debt levels go above or close to GDP levels. Hence, these economies become relatively distressed.

In the world of DCF, risk being the discounting factor is an adversary whereas in Contingent Claims Approach, risk is an ally for valuation, because as volatility increases, equity value also increases. The sub-prime crisis of 2008 provides an apt situation to test the risk-return relationship for world economies in the pre and post crisis periods.

In the existing literature, the major emphasis has been on cost of equity estimation using CAPM or other asset pricing benchmarks without verifying if such a relationship consistently holds in the real world. If this relationship is negative, then these paradigms will break down and cost of equity estimation will have to be done in a different way. Estrada [4] estimates CAPM based cost of equity for a sample of 28 emerging markets using two measures of risk viz. standard deviation and beta and their two counterpart downsize risk measures viz. semi deviation and downside beta. He finds downside risk to be a better measure for estimating the cost of equity for emerging markets. In continuation to his previous work, Estrada [5] conducts similar study for 23 developed markets and 27 Emerging Markets and shows superiority of downside beta over beta for estimating cost of equity. Collins [6] measures cost of equity using CAPM for 42 emerging economies, using 11 alternative risk measures and suggests that extent of global integration and market development is crucial for determining most appropriate cost of equity measure. Collins and Abrahamson [7] measure sec- 
toral cost of equity for African markets and find that cost of equity across sectors and markets declined between mid-1990s to early 2000s. Da, Guo and Jaggannathan [8] justify the continued use of CAPM for estimating cost of capital which is employed as discount factor in project evaluations for capital budgeting projects. Hasan, Hossain, Cheung and Habib [9] investigate the effect of corporate life cycle on cost of capital and find that cost of equity decreases as retained earnings as a proportion of total asset increases after controlling for other firm characteristics and unobserved heterogeneity. Abudy, Benninga and Shust [10] present a method for calculating cost of equity capital for private firms as compared to cost of equity capital of a publicly listed firm.

There have been few international studies which test the risk-return relationship in both linear as well as nonlinear form. Salvador, Floros and Arago [11] analyze risk-return relationship for 11 European stock markets. They find a significant positive non-linear risk return relationship after considering the current state of the sample markets. Chiang, Li and Zheng [12] examine the intertemporal capital asset pricing model for industry portfolio returns of 14 international markets and observe positive risk-return relationship during tranquil period. Aslanidis, Christiansen and Savva [13] adopt factor models to test intertemporal risk-return relationship for 13 European stock markets and find that such a relationship is generally negative. Wang and Khan [14] re-examine the risk-return relationship for U.S. market and find that risk return tradeoff is strongly time varying with state of the market. Liu [15] empirically estimates risk-return relationship for 12 international markets and finds it to be significantly positive after controlling for higher order moments.

The existing literature has suggested either the best method of finding out cost of equity for various markets or established a positive or negative risk-return relationship using linear or non-linear and static versus dynamic models. However, the literature is almost absent on the evaluation of risk-return relationship in and around the crisis period. Thus, rather than using risk-return relationship to find out cost of equity estimation, we should first test if such a relationship exists using standard asset pricing models. In order to empirically verify the risk-return relationship in and around the crisis period, we conduct the present study for the Global financial Crisis (GFC) ${ }^{1}$ period, popularly known as Sub Prime Crisis of 2008, with the following objectives: test the risk-return relationship in pre-GFC period for different types of markets; evaluate the risk-return relationship for the post GFC period; check the robustness of risk-return relationships using alternative risk measures; test if pre crisis risk-return relationship patterns can be used for predicting crisis; draw implications for corporate valuations and cost of equity estimation in the post crisis period.

We test the risk-return relationship in and around global financial crisis for 54 ${ }^{1}$ The crisis began in 2007 when the sub-prime customers failed in fulfilling their debt obligations and developed into a full blown international banking crisis with the collapse of Investment Bank Lehman Brothers on $15^{\text {th }}$ September, 2008. Massive bailouts of financial institutions and monetary and fiscal measures were employed to prevent possible collapse of the world financial system. The crisis was followed by a global economic downturn named as Great Recession [21] [22] [23]. 
MSCI countries divided into three market groups namely developed, emerging and frontier markets for a period from June 2005 to June 2016. We use four risk proxies viz. Standard Deviation, Semi Deviation, Beta and Downside Beta to test the risk-return relationship. We find that risk-return relationship is absent in the pre-crisis period. Thus, break down of such a relationship may be a key predictor of any forthcoming crisis. Further, the risk-return relationship is negative in the post crisis period using standard deviation measures. Thus, global economies seem to be "relatively distressed" and, hence, exhibit an option like behavior. This implies that option pricing model may be more useful for business valuation and cost of equity estimations compared to more popular DCF models. We re-verify our hypothesis by using data in and around the Asian crisis period of 1997. The risk-return relationship seems to break down for global financial markets again in the pre-crisis period. This lends support to our argument that an absence of risk-return relationship may be a good predictor of financial crisis.

The paper is divided into five sections including the present one. Data and their sources are discussed in Section 2. In Section 3 we describe the research methodology and estimation procedure. The empirical results are provided in Section 4 and summary and concluding remarks are given in the final section.

\section{Data and their Sources}

Sample of 54 Morgan Stanley Capital Indices (MSCI) equity market indices divided into three market groups, comprising of 21 Developed, 22 Emerging and 11 Frontier countries, and MSCI ALL Country World Index representing global market index has been taken from Bloomberg. MSCI provides Market Cap weighted Indexes for 69 Developed, Emerging and Frontier countries. However, due paucity of data for 15 countries for our sample period, we obtained data for 54 countries, the list of which is provided in Exhibit A. Bulgaria and Latvia which are classified as other countries in the MSCI list have been classified as Frontier Markets for the present study. The month end values of the sample indices have been taken from June 2005 to June 2016 which have been further used to estimate percentage monthly returns. The time period has been selected in order to obtain two equal, pre and post crisis study periods of five and a half years each (66 monthly observations). The first sub period named as the pre-crisis period (including crisis months) is from June 2005 to December 2010 and second sub period called as post crisis period is from January 2010 to June 2016. In order to check the robustness of risk-return relationship, we select another crisis period i.e. Asian crisis ${ }^{2}$ of 1997. For testing the risk-return

${ }^{2}$ Asian Crisis: The Asian crisis, also known as Currency Crisis, was a regional financial crisis that began in July 1997 in most of the East Asian countries and raised fears of a worldwide economic downturn due to financial contagion. It started in Thailand with the collapse of Thai Bhat and spread to most of the south east Asian countries namely Indonesia, South Korea, Laos, Philippines, Hong Kong and Malaysia to name a few. The crisis period is considered to be from July 1997 to December 1998. (source: Federal Reserve History of timeline of the Asian Financial Crises: http://www.federalreservehistory.org/Events/DetailView/51) 
Exhibit A. Key economic and financial characteristics of global financial markets. GDP is measure of size of economy, GDP growth shows economic development through GDP growth rate, Public Debt to GDP shows public debt exposure of the economy and Market Capto GDP shows size of the capital market.

\begin{tabular}{|c|c|c|c|c|c|}
\hline S.No. & Country & $\begin{array}{c}\text { GDP } \\
(\mathrm{PPP} \text { in Bn \$) } \\
(2015)\end{array}$ & $\begin{array}{l}\text { GDP Growth } \\
\text { (2015) }\end{array}$ & $\begin{array}{c}\text { Average } \\
\text { Debt to GDP } \\
(2015)\end{array}$ & $\begin{array}{c}\text { Market } \\
\text { Cap to GDP } \\
(2015)\end{array}$ \\
\hline \multicolumn{6}{|c|}{ Developed Markets } \\
\hline 1 & AUSTRIA & 426.65 & 0.96 & 95.71 & 25.49 \\
\hline 2 & AUSTRALIA & 1105.63 & 2.42 & 47.17 & 88.23 \\
\hline 3 & BELGIUM & 514.20 & 1.48 & 109.55 & 91.11 \\
\hline 4 & CANADA & 1584.69 & 0.94 & 54.71 & 102.61 \\
\hline 5 & DENMARK & 278.38 & 1.61 & 42.55 & 144.92 \\
\hline 6 & FINLAND & 231.65 & 0.27 & 59.42 & NA \\
\hline 7 & FRANCE & 2743.46 & 1.07 & 98.04 & 85.81 \\
\hline 8 & GERMANY & 3920.86 & 1.72 & 50.47 & 51.01 \\
\hline 9 & HONG KONG & 416.07 & 2.39 & 10.00 & 1029.36 \\
\hline 10 & IRELAND & 317.90 & 26.28 & 91.77 & 45.12 \\
\hline 11 & ISRAEL & 306.26 & 2.51 & 64.94 & 81.46 \\
\hline 12 & JAPAN & 5172.86 & 1.22 & 197.95 & 111.68 \\
\hline 13 & NETHERLANDS & 839.32 & 1.95 & 70.57 & 97.09 \\
\hline 14 & NEWZEALAND* & 174.40 & 2.43 & 56.73 & 42.35 \\
\hline 15 & NORWAY* & 321.97 & 1.61 & 22.88 & 50.16 \\
\hline 16 & SINGAPORE & 476.72 & 1.93 & 107.21 & 215.59 \\
\hline 17 & SPAIN & 1611.56 & 3.20 & 99.35 & 65.99 \\
\hline 18 & SWEDEN & 468.63 & 4.08 & 46.43 & 140.45 \\
\hline 19 & SWITZERLAND* & 517.65 & 0.84 & 22.67 & 226.49 \\
\hline 20 & UNITED KINGDOM* & 2720.26 & 2.19 & 107.63 & 132.71 \\
\hline \multirow[t]{2}{*}{21} & USA & 18036.65 & 2.60 & 97.84 & 138.98 \\
\hline & \multicolumn{5}{|c|}{ Emerging Markets } \\
\hline 22 & BRAZIL & 3216.17 & -3.77 & 67.48 & 27.20 \\
\hline 23 & CHILE & 418.83 & 2.25 & 17.37 & 78.49 \\
\hline 24 & CHINA & 19811.75 & 6.90 & 42.60 & 74.00 \\
\hline 25 & COLOMBIA & 666.81 & 3.05 & 67.12 & 29.49 \\
\hline 26 & CZECH REPUBLIC ${ }^{*}$ & 355.86 & 4.54 & 36.74 & 48.16 \\
\hline 27 & EGYPT & 1008.03 & 4.37 & 93.13 & 16.59 \\
\hline 28 & GREECE & 285.22 & -0.22 & 177.43 & 21.59 \\
\hline 29 & HUNGARY & 260.21 & 3.15 & 96.52 & 14.53 \\
\hline 30 & INDIA & 8019.95 & 8.01 & 69.50 & 71.80 \\
\hline 31 & INDONESIA & 2849.80 & 4.88 & 30.29 & 41.02 \\
\hline 32 & KOREA & 1756.02 & 2.79 & 39.74 & 89.04 \\
\hline 33 & MALAYSIA & 817.43 & 4.97 & 54.49 & 129.26 \\
\hline
\end{tabular}




\section{Continued}

\begin{tabular}{|c|c|c|c|c|c|}
\hline 34 & MEXICO & 2170.91 & 2.63 & 53.74 & 34.95 \\
\hline 35 & PERU & 393.13 & 3.25 & 22.65 & 29.89 \\
\hline 36 & PHILIPPINES & 744.52 & 6.07 & 44.70 & 81.57 \\
\hline 37 & POLAND & 1020.15 & 3.84 & 53.33 & 28.86 \\
\hline 38 & QATAR $^{*}$ & 316.40 & 3.55 & 34.93 & 86.59 \\
\hline 39 & RUSSIA $^{*}$ & 3470.24 & -2.83 & 13.52 & 28.79 \\
\hline 40 & SOUTH AFRICA & 727.79 & 1.30 & 51.70 & 231.86 \\
\hline 41 & TAIWAN & 530.00 & 0.70 & 31.60 & 159.23 \\
\hline 42 & THAILAND & 1113.83 & 2.94 & 44.41 & 87.37 \\
\hline \multirow[t]{2}{*}{43} & TURKEY & 1882.76 & 6.06 & 29.10 & 21.98 \\
\hline & \multicolumn{5}{|c|}{ Frontier Markets } \\
\hline 44 & ARGENTINA & 883.02 & 2.65 & 52.10 & 9.60 \\
\hline 45 & BANGLADESH $^{*}$ & 537.66 & 6.55 & 31.93 & 16.19 \\
\hline 46 & BULGARIA* $^{*}$ & 130.99 & 3.62 & 30.27 & 10.55 \\
\hline 47 & LATVIA* $^{*}$ & 49.28 & 2.71 & 56.86 & 3.22 \\
\hline 48 & LITHUANIA* & 84.06 & 1.78 & 14.54 & 9.00 \\
\hline 49 & MOROCCO & 274.06 & 4.51 & 64.70 & 45.66 \\
\hline 50 & PAKISTAN & 946.67 & 4.71 & 61.84 & 26.14 \\
\hline 51 & ROMANIA* & 437.34 & 3.94 & 44.96 & 19.21 \\
\hline 52 & SRI LANKA & 246.93 & 4.84 & 77.64 & 25.81 \\
\hline 53 & UKRAINE $^{*}$ & 340.54 & -9.77 & 70.26 & NA \\
\hline 54 & VIETNAM* & 553.42 & 6.68 & 62.20 & 26.85 \\
\hline
\end{tabular}

Source: World bank data sources. Note: ${ }^{*}$ : is put against the countries not included for Asian Crisis due to paucity of Data.

relationship in and around the Asian Crisis, monthly values of sample country Indices have been taken from June 1994 to June 2003 from Bloomberg. The rationale for taking the above mentioned time period is to divide the total time period of nine years into two equal halves of 4 and a half years (54 monthly observations) of pre(including crisis period) and post crisis period. The pre-crisis period is taken from June 1994 to December 1998 and post crisis period is from January 1999 to June 2003. The length of pre and post crisis periods during the Asian crisis is different from those in case of GFC owing to lack of data for some of the sample countries for the period of early 1990s. The values so obtained have been again converted into percentage returns for further estimations. The sample data of 40 countries out of the originally selected 54 countries has been taken from Bloomberg. The 14 countries were omitted from the sample due to paucity of data for the period under investigation.

\section{Methodology}

Since last 50 years the debate is continuing among both, practitioners as well as academics, with regards to the relevance of CAPM as a model to derive the risk 
return relationship. The risk in this model is measured by Beta which is a sensitivity coefficient that captures how asset returns co-move with the market returns. Beta is a measure of non-diversifiable or systematic risk. However, in markets which offer limited diversification possibilities, total risk may matter which is generally measured using standard deviation of returns. Standard deviation can be an appropriate measure of risk only when the underlying distribution of returns is symmetric and normal. However, both these conditions have been questioned in the available empirical literature. Hence, it has been suggested that semi-deviation, on the other hand is a more acceptable measure of risk [16]. The reasons given in favor of semi-deviation are first investors dislike downside volatility and not upside volatility. Second, semi-deviation as a measure of risk is more useful for asymmetric distributions of returns and equally useful as standard deviation for symmetric return distributions. Finally, it combines the information given by two statistics i.e. standard deviation and skewness, into one measure, thus making it possible to use single factor model for estimating returns. Furthermore, it can be used to generate an alternative behavioral hypothesis, Mean-Semi-Variance (Semi-Deviation) Behavior (MSB) [4] [16].

Apart from standard deviation and semi-deviation as risk measures, Estrada has proposed to replace the CAPM beta by a measure called downside beta [5] He finds that cost of equity estimations based on beta for developed and emerging economies gave contradictory results. In his study cost of equity for developed economies came out to be higher than that of emerging economies based on standard CAPM estimations. It is generally believed that emerging markets, being more risky, should have higher cost of equity estimations. On the contrary while using downside beta, he finds that cost of equity of emerging markets is higher than that of developed markets and that is a more realistic depiction considering the risk-return relationship.

Based on Estrada's findings we investigate the risk-return relationship by taking four measures of risk viz. standard deviation, semi-deviation, beta and downside beta. Standard deviation and semi deviation of returns have been estimated using standard statistical formulae, while beta has been estimated as the slope of regression of country returns on global index returns. Downside beta has been estimated as the slope of country returns regressed on All World Index returns using the months for which the All World Index is below its average value.

We estimate the mean correlations of returns for the countries within group as well as pairwise combinations of developed, emerging and frontier markets. The correlations have been done separately for total period and two sub periods. The correlations have been estimated to verify how closely related returns of countries are within a group. Further, we also try to see how correlated are developed, emerging and frontier markets, for which we have estimated pairwise correlations of these groups. We have estimated these correlations for total pe- 
riod as well as sub periods to identify changes in association, if any, for pre and post global financial crisis.

After reporting mean correlations, we also present the mean correlations between 1) returns and the alternative risk measures and 2) between alternative risk measures. We have estimated these correlations for total period as well as two sub periods. The correlations have been estimated to check if risk return relationships have changed for different countries in pre and post crisis period.

Risk return relationships have been explicitly tested using bivariate cross sectional regressions, run for all three market groups taken together as well as separately for both the sub periods.

The equation is given by:

$$
M R_{i}=\kappa_{0}+\kappa_{1} R V_{i}+U_{i}
$$

where, $M R_{i}$ and $R V_{i}$ stand for mean return and risk measure, respectively, $\Lambda_{0}$ and $\Lambda_{1}$ are estimated parameters, $U_{i}$ is an error term, and $i$ indexes markets.

All the regressions have been estimated using Newey West technique in order to take care of heteroscedasticity and autocorrelations.

Finally, to re-verify how risk-return relationships are observed in around financial crisis periods, we investigate these relationships for the sample countries for Asian crisis of 1997. The methodology adopted for constructing the risk factors and establishing the risk-return relationship is similar as used for global financial crisis. We test risk-return relationship using bivariate regressions, firstly by taking a sample of 12 Asian countries out of the 40 countries selected and next by taking a sample of 40 countries (including Non-Asian countries for which data was available) single block. The rationale for taking both Asian as well as Non-Asian countries is that latter may have had exposures in Asian economies owing to international trade and investments, particularly in a world which is highly globalized.

\section{Empirical Results}

\subsection{Descriptive Statistics}

The first step of the analysis consists of computing the descriptive statistics for both the sub periods of the three market groups under study. We report the descriptive statistics in Table 1 . In sub period 1 the average monthly returns given by developed markets is $0.47 \%$ ( $5.64 \%$ annually) and the average monthly volatility is $07.3 \%$ ( $87.6 \%$ annually). The monthly average skewness and kurtosis measures for developed markets are -0.713 and 4.662 respectively, suggesting these markets are negatively skewed and leptokurtic. The highest and lowest returns among the developed countries have been given by Canada $(13.92 \%$ annually) and Ireland (-17.28\% annually) respectively. The two highest and lowest volatile countries among the developed economies are Austria (124.44\% annually) and USA (59.04\% annually) respectively. The average monthly returns and volatility measures for emerging markets for sub period 1 are $1.53 \%$ (18.36\% annually) and $9.51 \%$ (114.12\% annually) respectively. Their average monthly 
Table 1. Descriptive statistics for global financial markets. In this table we provide the descriptive statistics for all the three market groups separately for both the sub periods. J.B. Stat. stands for Jarque-Bera Statistic and L1 L2 and L3 are the lagged values of autocorrelations.

\begin{tabular}{|c|c|c|c|c|c|c|c|c|}
\hline \multicolumn{9}{|c|}{ Panel A: Pre Crisis Descriptive Statistics } \\
\hline \multicolumn{9}{|c|}{ Developed Countries } \\
\hline Countries & M.R. & S.D. & SKEWNESS & KURTOSIS & J.B. Stat. & \multicolumn{3}{|c|}{ Autocorrelations } \\
\hline & & & & & & $\mathrm{L} 1$ & $\mathrm{~L} 2$ & L3 \\
\hline AUSTRIA & 0.0017 & 0.1037 & -0.8227 & 5.2972 & 22.2899 & 0.2760 & 0.1200 & 0.1550 \\
\hline AUSTRALIA & 0.0102 & 0.0909 & 0.1403 & 4.3306 & 5.1627 & 0.0030 & 0.1320 & 0.0650 \\
\hline BELGIUM & -0.0018 & 0.0824 & -1.7162 & 8.0887 & 105.1796 & 0.3860 & -0.0010 & 0.1720 \\
\hline CANADA & 0.0116 & 0.0729 & -0.5937 & 5.2711 & 18.3350 & 0.1680 & 0.1600 & 0.0120 \\
\hline DENMARK & 0.0114 & 0.0701 & -1.0911 & 5.9947 & 38.3295 & 0.2750 & 0.0100 & 0.1910 \\
\hline FINLAND & 0.0037 & 0.0847 & -0.3431 & 3.7621 & 2.9361 & 0.2360 & -0.0920 & 0.0800 \\
\hline FRANCE & 0.0033 & 0.0709 & -0.6595 & 3.6518 & 6.0422 & 0.1600 & -0.1080 & 0.1810 \\
\hline GERMANY & 0.0076 & 0.0749 & -0.7523 & 3.8376 & 8.2791 & 0.1640 & -0.1120 & 0.1740 \\
\hline HONG KONG & 0.0096 & 0.0688 & -0.3709 & 4.6568 & 9.1991 & 0.2430 & 0.1550 & 0.0530 \\
\hline IRELAND & -0.0144 & 0.0838 & -0.9354 & 3.6854 & 11.0826 & 0.2950 & 0.1500 & 0.3780 \\
\hline ISRAEL & 0.0084 & 0.0552 & -0.8009 & 3.9593 & 9.7312 & 0.1850 & 0.0940 & 0.0870 \\
\hline JAPAN & 0.0025 & 0.0502 & -0.4614 & 3.8004 & 4.1658 & 0.3410 & -0.0830 & 0.1000 \\
\hline NETHERLANDS & 0.0052 & 0.0725 & -0.8839 & 4.5881 & 15.7651 & 0.1880 & -0.0680 & 0.2320 \\
\hline NEWZEALAND & -0.0016 & 0.0693 & -0.7034 & 3.8138 & 7.3746 & 0.2130 & 0.0600 & 0.3020 \\
\hline SINGAPORE & 0.0101 & 0.0739 & -0.6530 & 7.0298 & 50.0952 & 0.2870 & 0.2030 & 0.0030 \\
\hline SPAIN & 0.0049 & 0.0835 & -0.6248 & 4.2446 & 8.6829 & 0.1460 & -0.1160 & 0.1640 \\
\hline SWEDEN & 0.0102 & 0.0805 & -0.4908 & 4.8867 & 12.6274 & 0.2070 & 0.0190 & 0.2700 \\
\hline SWITZERLAND & 0.0064 & 0.0515 & -0.6629 & 3.3526 & 5.2546 & 0.2190 & 0.0000 & 0.2100 \\
\hline $\begin{array}{l}\text { UNITED } \\
\text { KINGDOM }\end{array}$ & 0.0017 & 0.0583 & -0.4693 & 4.3709 & 7.7065 & 0.3440 & 0.1140 & 0.2210 \\
\hline USA & 0.0023 & 0.0492 & -0.8728 & 4.3715 & 13.7573 & 0.2710 & -0.0350 & 0.1670 \\
\hline NORWAY & 0.0061 & 0.0775 & -1.2151 & 4.9141 & 26.3157 & 0.1860 & 0.0910 & 0.0170 \\
\hline \multicolumn{9}{|c|}{ Emerging Countries } \\
\hline Countries & M.R. & S.D. & SKEWNESS & KURTOSIS & J.B. Stat. & \multicolumn{3}{|c|}{ Autocorrelations } \\
\hline & & & & & & $\mathrm{L} 1$ & $\mathrm{~L} 2$ & L3 \\
\hline BRAZIL & 0.0239 & 0.1030 & -0.5133 & 4.0427 & 5.9776 & 0.2000 & 0.1830 & 0.0460 \\
\hline CHILE & 0.0179 & 0.0638 & -1.0874 & 6.9844 & 57.5241 & 0.2480 & 0.1710 & -0.1820 \\
\hline CHINA & 0.0189 & 0.0905 & -0.6504 & 3.4160 & 5.2063 & 0.1650 & 0.1370 & -0.0490 \\
\hline COLOMBIA & 0.0277 & 0.0946 & -0.6995 & 3.9078 & 7.7651 & 0.2450 & -0.0360 & -0.0380 \\
\hline CZECH REPUBLIC & 0.0113 & 0.0886 & -0.5739 & 4.2479 & 8.0251 & 0.2280 & -0.0570 & 0.1480 \\
\hline EGYPT & 0.0134 & 0.1023 & -0.5061 & 3.9543 & 5.4029 & 0.2260 & -0.0250 & 0.1730 \\
\hline GREECE & -0.0066 & 0.1081 & -0.3088 & 4.6078 & 8.2812 & 0.2410 & -0.0500 & 0.0910 \\
\hline HUNGARY & 0.0076 & 0.1193 & -0.7527 & 4.7722 & 15.0932 & 0.2690 & 0.0200 & 0.1170 \\
\hline INDIA & 0.0211 & 0.1030 & -0.1083 & 4.6121 & 7.3858 & 0.1760 & 0.0390 & 0.0290 \\
\hline INDONESIA & 0.0238 & 0.1060 & -0.6694 & 5.7197 & 25.6540 & 0.2520 & -0.0270 & 0.1890 \\
\hline
\end{tabular}




\section{Continued}

\begin{tabular}{|c|c|c|c|c|c|c|c|c|}
\hline KOREA & 0.0143 & 0.0955 & -0.2688 & 4.1409 & 4.4410 & 0.0590 & 0.0220 & 0.2310 \\
\hline MALAYSIA & 0.0134 & 0.0559 & -0.4859 & 4.2220 & 6.8045 & 0.2630 & 0.1810 & 0.2150 \\
\hline MEXICO & 0.0158 & 0.0771 & -1.1238 & 6.2245 & 43.1284 & 0.2360 & 0.0780 & 0.1740 \\
\hline PERU & 0.0312 & 0.1070 & -0.6491 & 4.3210 & 9.5759 & -0.0960 & 0.0890 & 0.1490 \\
\hline PHILIPPINES & 0.0154 & 0.0758 & -0.4839 & 4.3512 & 7.7116 & 0.0510 & 0.1300 & 0.0590 \\
\hline POLAND & 0.0124 & 0.1099 & -0.4461 & 3.7311 & 3.7141 & 0.1200 & -0.0610 & 0.2030 \\
\hline QATAR & 0.0017 & 0.1017 & -0.0975 & 3.3908 & 0.5246 & 0.0910 & 0.0420 & 0.0960 \\
\hline SOUTH AFRICA & 0.0166 & 0.0876 & -0.4322 & 3.1125 & 2.1210 & 0.1000 & -0.0560 & 0.0610 \\
\hline TAIWAN & 0.0077 & 0.0797 & -0.1685 & 2.8349 & 0.3930 & 0.1690 & 0.1660 & 0.0520 \\
\hline THAILAND & 0.0150 & 0.0844 & -0.8535 & 5.6772 & 28.1439 & 0.2070 & -0.0820 & 0.2210 \\
\hline TURKEY & 0.0184 & 0.1253 & -0.4244 & 3.2808 & 2.2316 & 0.0060 & 0.0570 & 0.1050 \\
\hline RUSSIA & 0.0152 & 0.1128 & -0.4496 & 3.9977 & 4.9605 & 0.3650 & 0.2570 & 0.1390 \\
\hline \multicolumn{9}{|c|}{ Frontier Countries } \\
\hline \multirow[t]{2}{*}{ Countries } & M.R. & S.D. & SKEWNESS & KURTOSIS & J.B. Stat. & \multicolumn{3}{|c|}{ Autocorrelations } \\
\hline & & & & & & L1 & L2 & L3 \\
\hline ARGENTINA & 0.0209 & 0.1132 & -0.8731 & 5.3497 & 23.9262 & 0.2470 & 5.4944 & 0.1310 \\
\hline BANGLADESH & 0.0266 & 0.0503 & 1.7629 & 6.0868 & 11.8947 & -0.2270 & -0.3300 & 0.0810 \\
\hline BULGARIA & -0.0098 & 0.1113 & -1.3573 & 7.2905 & 71.9619 & 0.4190 & 0.1160 & 0.2920 \\
\hline LATVIA & 0.0023 & 0.0820 & -0.6509 & 4.0057 & 7.5547 & 0.3390 & 0.1940 & 0.2240 \\
\hline Lithuania & -0.0133 & 0.1818 & -0.6606 & 7.8522 & 30.5578 & 0.2300 & 0.2230 & 0.0880 \\
\hline MOROCCO & 0.0155 & 0.0690 & 0.0467 & 3.8425 & 2.0057 & 0.0310 & 0.2380 & 0.0760 \\
\hline PAKISTAN & 0.0052 & 0.1067 & -1.7339 & 9.6333 & 156.4089 & 0.1670 & -0.0850 & -0.0460 \\
\hline ROMANIA & 0.0102 & 0.1518 & -0.5345 & 4.6349 & 9.6982 & 0.2090 & -0.0670 & 0.0640 \\
\hline SRI LANKA & 0.0172 & 0.1175 & 1.9441 & 11.1557 & 227.8945 & 0.1710 & 0.1660 & -0.0380 \\
\hline UKRAINE & -0.0104 & 0.1392 & -0.0532 & 3.9075 & 1.9133 & 0.3920 & 0.0930 & 0.1080 \\
\hline VIETNAM & 0.0110 & 0.1593 & 0.8919 & 4.3338 & 10.1289 & 0.3400 & -0.1930 & -0.1460 \\
\hline \multicolumn{9}{|c|}{ Panel B: Post Crisis Descriptive Statistics } \\
\hline \multicolumn{9}{|c|}{ Developed Countries } \\
\hline \multirow[t]{2}{*}{ Countries } & MEAN & $\begin{array}{l}\text { STD. } \\
\text { DEV }\end{array}$ & SKEWNESS & KURTOSIS & J.B. Stat. & \multicolumn{3}{|c|}{ Autocorrelations } \\
\hline & & & & & & L1 & L2 & L3 \\
\hline AUSTRIA & -0.0058 & 0.0718 & -0.5346 & 3.6281 & 4.1646 & 0.0410 & -0.0020 & -0.0130 \\
\hline AUSTRALIA & -0.0009 & 0.0606 & -0.0658 & 3.8997 & 2.2391 & -0.1630 & -0.0140 & -0.0560 \\
\hline BELGIUM & 0.0088 & 0.0475 & 0.0475 & 2.6273 & 0.4007 & -0.0950 & 0.0070 & -0.0500 \\
\hline CANADA & -0.0026 & 0.0459 & -0.2416 & 3.4402 & 1.1570 & -0.0730 & 0.0970 & -0.1130 \\
\hline DENMARK & 0.0100 & 0.0521 & -0.0488 & 3.8759 & 2.1037 & 0.0710 & -0.0450 & -0.0020 \\
\hline FINLAND & 0.0004 & 0.0622 & -0.1776 & 3.7112 & 1.7116 & 0.0250 & 0.0100 & 0.0020 \\
\hline FRANCE & 0.0017 & 0.0552 & -0.2191 & 2.8419 & 0.5878 & -0.0860 & 0.0100 & 0.0400 \\
\hline GERMANY & 0.0029 & 0.0617 & -0.3412 & 3.7229 & 2.6760 & 0.0100 & -0.2100 & 0.0610 \\
\hline HONG KONG & 0.0024 & 0.0547 & -0.4752 & 3.7950 & 4.1584 & -0.1680 & -0.0900 & 0.1240 \\
\hline IRELAND & 0.0108 & 0.0563 & 0.4493 & 3.4553 & 2.7486 & -0.1850 & 0.0790 & 0.0170 \\
\hline
\end{tabular}




\section{Continued}

\begin{tabular}{|c|c|c|c|c|c|c|c|c|}
\hline ISRAEL & -0.0021 & 0.0529 & -0.0726 & 3.8741 & 2.1266 & -0.1310 & -0.1170 & 0.1620 \\
\hline JAPAN & 0.0021 & 0.0407 & -0.2057 & 3.2144 & 0.5827 & -0.0220 & -0.0710 & -0.0550 \\
\hline NETHERLANDS & 0.0047 & 0.0487 & -0.1601 & 2.9312 & 0.2905 & -0.1190 & -0.0460 & 0.1140 \\
\hline NEWZEALAND & 0.0062 & 0.0565 & 0.1250 & 3.1221 & 0.2097 & -0.0540 & -0.0230 & 0.0100 \\
\hline SINGAPORE & 0.0028 & 0.0363 & 0.1540 & 3.7660 & 1.8459 & 0.0370 & -0.1530 & 0.0650 \\
\hline SPAIN & -0.0011 & 0.0716 & 0.3265 & 3.2760 & 1.3613 & -0.0870 & 0.0620 & 0.0880 \\
\hline SWEDEN & 0.0009 & 0.0547 & 0.0171 & 3.6901 & 1.2930 & -0.0890 & -0.0690 & -0.0130 \\
\hline SWITZERLAND & 0.0038 & 0.0415 & -0.5218 & 3.4525 & 3.5043 & -0.1300 & 0.0420 & 0.1410 \\
\hline $\begin{array}{l}\text { UNITED } \\
\text { KINGDOM }\end{array}$ & 0.0004 & 0.0440 & -0.1415 & 3.0285 & 0.2192 & -0.2530 & 0.0170 & 0.0850 \\
\hline USA & 0.0084 & 0.0344 & -0.0316 & 3.5028 & 0.6956 & -0.1210 & -0.1050 & -0.0050 \\
\hline NORWAY & 0.0003 & 0.0415 & -0.2409 & 3.4860 & 1.2685 & 0.0990 & -0.1460 & -0.1680 \\
\hline & & & Emerging $C$ & Countries & & & & \\
\hline Countries & M.R. & S.D. & SKEWNESS & KURTOSIS & J.B. Stat. & Aut & tocorrelat & ions \\
\hline & & & & & & L1 & L2 & L3 \\
\hline BRAZIL & -0.0128 & 0.0910 & 0.6621 & 4.2094 & 8.7105 & 0.0060 & -0.0840 & -0.1340 \\
\hline CHILE & -0.0098 & 0.0611 & 0.1147 & 4.0466 & 3.1091 & -0.1310 & 0.0120 & -0.1470 \\
\hline CHINA & -0.0006 & 0.0644 & -0.0739 & 3.4655 & 0.6461 & 0.0050 & -0.0690 & -0.0130 \\
\hline COLOMBIA & -0.0091 & 0.0724 & 0.2445 & 3.1222 & 0.6882 & 0.0530 & 0.0990 & -0.0350 \\
\hline CZECH REPUBLIC & -0.0076 & 0.0651 & 0.3823 & 3.2141 & 1.7073 & -0.0940 & 0.0300 & -0.0900 \\
\hline EGYPT & -0.0008 & 0.0882 & 0.3111 & 3.6964 & 2.3616 & -0.1060 & -0.0240 & 0.0610 \\
\hline GREECE & -0.0229 & 0.1312 & -0.2966 & 3.0437 & 0.9582 & 0.0360 & 0.0680 & 0.1870 \\
\hline HUNGARY & -0.0002 & 0.0920 & -0.0425 & 3.8785 & 2.1096 & -0.0320 & -0.0960 & 0.1310 \\
\hline INDIA & -0.0007 & 0.0697 & 0.2476 & 3.2905 & 0.8928 & -0.0780 & -0.2500 & 0.1520 \\
\hline INDONESIA & -0.0010 & 0.0641 & -0.3861 & 3.1823 & 1.7047 & 0.0170 & -0.1000 & 0.1280 \\
\hline KOREA & -0.0006 & 0.0587 & 0.2168 & 3.3033 & 0.7582 & -0.0370 & -0.2100 & 0.0720 \\
\hline MALAYSIA & -0.0031 & 0.0461 & -0.1308 & 4.6186 & 7.2812 & -0.0620 & -0.0270 & -0.0020 \\
\hline MEXICO & -0.0019 & 0.0534 & 0.0883 & 3.7237 & 1.5029 & -0.1250 & -0.1740 & 0.1010 \\
\hline PERU & -0.0055 & 0.0690 & 0.0359 & 2.8186 & 0.1031 & -0.0730 & 0.0650 & 0.1910 \\
\hline PHILIPPINES & 0.0089 & 0.0531 & -0.1738 & 2.6682 & 0.6255 & -0.0440 & -0.1250 & 0.1830 \\
\hline POLAND & -0.0075 & 0.0751 & 0.1590 & 3.4183 & 0.7477 & -0.1000 & -0.0840 & 0.1350 \\
\hline QATAR & 0.0009 & 0.0523 & -1.0995 & 7.1684 & 60.1542 & -0.3170 & 0.0390 & 0.1520 \\
\hline SOUTH AFRICA & -0.0040 & 0.0611 & 0.0179 & 3.2617 & 0.1889 & -0.1330 & -0.1260 & -0.0520 \\
\hline TAIWAN & -0.0008 & 0.0473 & -0.2761 & 2.5694 & 1.3282 & -0.0110 & -0.0280 & 0.0000 \\
\hline THAILAND & 0.0020 & 0.0618 & -0.3657 & 2.9884 & 1.4495 & -0.0220 & -0.1880 & 0.0890 \\
\hline TURKEY & -0.0040 & 0.0851 & 0.2033 & 2.4006 & 1.4208 & 0.0980 & -0.1770 & -0.1930 \\
\hline RUSSIA & -0.0063 & 0.0899 & 0.0251 & 3.7074 & 1.3621 & 0.0020 & -0.1950 & -0.0150 \\
\hline \multicolumn{9}{|c|}{ Frontier Countries } \\
\hline \multirow[t]{2}{*}{ Countries } & M.R. & S.D. & SKEWNESS & KURTOSIS & J.B. Stat. & \multicolumn{3}{|c|}{ Autocorrelations } \\
\hline & & & & & & L1 & L2 & L3 \\
\hline ARGENTINA & 0.0029 & 0.1229 & 0.4524 & 4.6734 & 9.8009 & -0.0260 & -0.0590 & 0.0070 \\
\hline
\end{tabular}


Continued

\begin{tabular}{ccccccccc}
\hline BANGLADESH & -0.0041 & 0.0807 & -0.5947 & 4.7557 & 12.1795 & -0.0700 & -0.1360 & 0.0590 \\
BULGARIA & -0.0079 & 0.0857 & 1.3500 & 7.4385 & 73.0969 & 0.1430 & 0.1490 & 0.3140 \\
LATVIA & 0.0066 & 0.0612 & 1.4811 & 10.0282 & 157.5427 & 0.0180 & -0.0700 & -0.0370 \\
Lithuania & -0.0028 & 0.0426 & -0.2858 & 3.7422 & 2.3771 & -0.1350 & 0.1000 & -0.1370 \\
MOROCCO & -0.0079 & 0.0422 & 0.4903 & 3.0204 & 2.6053 & 0.0500 & -0.1420 & -0.0590 \\
PAKISTAN & 0.0044 & 0.0585 & -0.1341 & 2.9522 & 0.2011 & -0.1980 & -0.1030 & 0.0610 \\
ROMANIA & 0.0054 & 0.0756 & -0.5282 & 3.6325 & 4.1063 & 0.0060 & 0.0890 & -0.0390 \\
SRI LANKA & -0.0056 & 0.0612 & 0.0193 & 3.1847 & 0.0964 & -0.1380 & 0.0140 & 0.0450 \\
UKRAINE & -0.0268 & 0.1120 & -0.3849 & 2.9598 & 1.6093 & -0.0030 & -0.0650 & 0.1860 \\
VIETNAM & -0.0033 & 0.0676 & 0.1741 & 3.2612 & 0.5130 & -0.0880 & -0.0710 & -0.0040 \\
\hline
\end{tabular}

skewness and kurtosis measures are -0.534 and 4.343 respectively. Peru (37.44\% annually) and Greece $(-7.92 \%$ annually) are the highest and lowest return providing countries respectively among emerging markets, while Turkey (150.36\%) and Malaysia (67.08\%) are the most and least volatile countries respectively. The monthly average returns and volatility among the Frontier markets are found to be $0.69 \%$ ( $8.28 \%$ annually) and $11.65 \%$ (139.80\% annually) respectively. The monthly average skewness and kurtosis among these countries are -0.110 and 6.190 respectively implying these countries to be highly leptokurtic. Among frontier markets Bangladesh (31.92\% annually) provided the highest returns while Lithuania ( $-15.96 \%$ annually) provided the least return in sub period 1 . The interesting observation is that the Lithuania again (218.16\% annually) exhibits highest return volatility while Bangladesh (60.36\%) provides least return volatile for the sample sub period.

In sub period 2 we find that the monthly average returns for developed countries continue to be positive but decreased to $0.26 \%$ ( $3.12 \%$ annually) while monthly average volatility was recorded at $5.19 \%$ (62.28\% annually). However, it is observed that the average skewness and kurtosis parameters sober down to -0.112 and 3.445 respectively for sub period 2. In terms of returns Ireland $(12.96 \%$ annually) Canada $(-3.12 \%$ annually) are the highest and lowest return performing countries which is a reversal of performance when compared with sub period 1. Austria ( $861.6 \%$ annually) is the highest while USA $(41.28 \%)$ is the least volatile country among the developed market group which is in line with sub period 1 results. The average monthly return and volatility among emerging markets are found to be -0.40 monthly $(-4.8 \%$ annually) and 7.05 monthly (84.6\% annually) respectively. The monthly average skewness and kurtosis measures are -0.006 and 3.536. Although the returns distributions among emerging markets have move towards normality, however, these countries are worst hit countries with negative returns in post crisis period. Philippines provide the highest returns while Greece continues to be the worst performing country post crisis. The two highest and lowest volatile economies are Greece and Malaysia respectively. Frontier markets returns have also gone in negative 
territory in sub period $2,-0.35 \%$ monthly $(-4.2 \%$ annually) and their monthly average volatility has been $11.65 \%$ (139.80\% annually). Contrary to developed and emerging markets, the return distributions have become more skewed ( $0.185 \%$ monthly) and Leptokurtic ( $4.513 \%$ monthly) in post crisis period. The best performing country has been Latvia while Ukraine reported lowest returns. In terms of returns volatility, Argentina is the most volatile country while Morocco exhibits least volatility.

To sum up, we can say that on the basis of risk-return relationship, emerging markets have performed best in pre-crisis period followed by developed markets. Frontier markets do not play any significant role in country selection process in the pre-crisis period. On the contrary, in the post crisis period all the three market groups have performed poorly with developed markets as the only group in positive return territory. The findings have implications for country selection in the global portfolio formation process.

\subsection{Return Correlations}

Next, we examined the return correlations for countries within each market group as well as across the market groups. The average correlation coefficients are shown in Table 2 for sub periods 1 and 2 separately. In sub period 1, both within group as well as between group mean correlations of returns are above $65 \%$ except for frontier markets group where such correlations are relatively lower. Taking the mean of all average correlation coefficients the global financial markets report correlation of $54 \%$. In the post-crisis period, the associations within and between the market group correlations have decreased with the mean of all correlation coefficients to be $40 \%$, thus, the global financial crisis has led to de-coupling effect which is reflected in weaker associations between global financial markets. The lower post crisis period correlations have positive implications for global portfolio diversification.

\subsection{Measuring Risk-Return Correlations and the Association between Alternative Risk Measures}

In the next step, we check the correlations of returns with the four risks measures used for study as well among the four risk measures (see Table 3). Surprisingly, the risk and returns measures exhibit negative correlations both for pre as well as post-crisis period. The findings are robust for alternative risk measures which have strong negative implications for standard asset pricing framework which envisages positive relationship between risk and returns. In terms of correlations among risk measures, we find that by a large risk measures are highly correlated in both the sub periods, although this relationship sobers down in sub period 2. Hence, our risk measures seem to be highly correlated risk proxies. Therefore, the choice of risk measure should not significantly impact our asset pricing analysis. The choice of risk proxy, however, matters more in sub period 2 especially for frontier markets, given lower associations between alternative risk measures. 
Table 2. Return correlations among global financial markets. The table shows the mean correlations between the market groups as well as among all the three market groups combined together. The correlations have been shown for Pre as well as post crisis period separately in two panels.

\begin{tabular}{ccccc}
\hline \multicolumn{5}{c}{ Panel A: Pre-Crisis Period } \\
\hline Market Group & Developed & Emerging & Frontier & Combined Market Groups \\
\hline Developed & 0.7377 & 0.6831 & 0.5078 & \\
Emerging & 0.6831 & 0.6485 & 0.4788 & \\
Frontier & 0.5078 & 0.4788 & 0.3651 & 0.5393 \\
Combined Market Groups & & & & \\
\hline & \multicolumn{5}{c}{ Panel B: Post-Crisis Period } & \\
\hline Market Group & Developed & Emerging & Frontier & Combined Market Groups \\
\hline Developed & 0.5554 & 0.4855 & 0.3876 & \\
Emerging & 0.4855 & 0.4876 & 0.3462 & \\
Frontier & 0.3876 & 0.3462 & 0.2031 & \\
Combined Market Groups & & & & 0.4004 \\
\hline
\end{tabular}

Table 3. Return-Risk associations and mean correlations between alternative risk measures. This table shows the correlations in two ways i.e. by showing the correlations between the mean returns and alternative risk measures as well as the mean correlations among the alternative risk measures of the three market groups. The table has been divided into two panels to depict the relationships among the variables in pre and post crisis periods separately. M.R., S.D., SE.D., $\beta$ and $\mathrm{D} \beta$ imply mean returns, standard deviation, semi-deviation, beta and downside beta respectively.

\begin{tabular}{|c|c|c|c|c|c|}
\hline \multicolumn{6}{|c|}{ Panel A: Pre-Crisis Period } \\
\hline \multicolumn{6}{|c|}{ Developed Countries } \\
\hline Measures & M.R. & S.D & SE.D. & $\beta$ & $\mathrm{D} \beta$ \\
\hline M.R. & 1.0000 & -0.1069 & -0.2156 & -0.2360 & -0.2050 \\
\hline S.D & -0.1069 & 1.0000 & 0.9165 & 0.7550 & 0.8095 \\
\hline SE.D. & -0.2156 & 0.9165 & 1.0000 & 0.8351 & 0.9225 \\
\hline$\beta$ & -0.2360 & 0.7550 & 0.8351 & 1.0000 & 0.9150 \\
\hline $\mathrm{D} \beta$ & -0.2050 & 0.8095 & 0.9225 & 0.9150 & 1.0000 \\
\hline \multicolumn{6}{|c|}{ Emerging Countries } \\
\hline Measures & M.R. & S.D & SE.D. & $\beta$ & $\mathrm{D} \beta$ \\
\hline M.R. & 1.0000 & -0.0110 & 0.0767 & -0.1067 & -0.2353 \\
\hline S.D & -0.0110 & 1.0000 & 0.9397 & 0.8832 & 0.8296 \\
\hline SE.D. & 0.0767 & 0.9397 & 1.0000 & 0.8347 & 0.8606 \\
\hline$\beta$ & -0.1067 & 0.8832 & 0.8347 & 1.0000 & 0.8841 \\
\hline $\mathrm{D} \beta$ & -0.2353 & 0.8296 & 0.8606 & 0.8841 & 1.0000 \\
\hline \multicolumn{6}{|c|}{ Frontier Countries } \\
\hline Measures & M.R. & S.D & SE.D. & $\beta$ & $\mathrm{D} \beta$ \\
\hline M.R. & 1.0000 & -0.5439 & -0.7126 & -0.4995 & -0.4529 \\
\hline S.D & -0.5439 & 1.0000 & 0.8388 & 0.6776 & 0.4921 \\
\hline SE.D. & -0.7126 & 0.8388 & 1.0000 & 0.6554 & 0.4884 \\
\hline
\end{tabular}


Continued

\begin{tabular}{|c|c|c|c|c|c|}
\hline$\beta$ & -0.4995 & 0.6776 & 0.6554 & 1.0000 & 0.9607 \\
\hline $\mathrm{D} \beta$ & -0.4529 & 0.4921 & 0.4884 & 0.9607 & 1.0000 \\
\hline \multicolumn{6}{|c|}{ Combined Market Groups } \\
\hline Measures & M.R. & S.D & SE.D. & $\beta$ & $\mathrm{D} \beta$ \\
\hline M.R. & 1.0000 & -0.1023 & -0.2717 & -0.1436 & -0.2076 \\
\hline S.D & -0.1023 & 1.0000 & 0.8811 & 0.5387 & 0.5072 \\
\hline SE.D. & -0.2717 & 0.8811 & 1.0000 & 0.5741 & 0.5495 \\
\hline$\beta$ & -0.1436 & 0.5387 & 0.5741 & 1.0000 & 0.9220 \\
\hline $\mathrm{D} \beta$ & -0.2076 & 0.5072 & 0.5495 & 0.9220 & 1.0000 \\
\hline \multicolumn{6}{|c|}{ Panel B: Post-Crisis Period } \\
\hline \multicolumn{6}{|c|}{ Developed Countries } \\
\hline Measures & M.R. & S.D & SE.D. & $\beta$ & $\mathrm{D} \beta$ \\
\hline M.R. & 1.0000 & -0.3564 & -0.5639 & -0.1277 & -0.2905 \\
\hline S.D & -0.3564 & 1.0000 & 0.8668 & 0.5799 & 0.5492 \\
\hline SE.D. & -0.5639 & 0.8668 & 1.0000 & 0.4687 & 0.6565 \\
\hline$\beta$ & -0.1277 & 0.5799 & 0.4687 & 1.0000 & 0.7567 \\
\hline $\mathrm{D} \beta$ & -0.2905 & 0.5492 & 0.6565 & 0.7567 & 1.0000 \\
\hline \multicolumn{6}{|c|}{ Emerging Countries } \\
\hline Measures & M.R. & S.D & SE.D. & $\beta$ & $\mathrm{D} \beta$ \\
\hline M.R. & 1.0000 & -0.6795 & -0.6412 & -0.4810 & -0.3175 \\
\hline S.D & -0.6795 & 1.0000 & 0.9244 & 0.6400 & 0.5556 \\
\hline SE.D. & -0.6412 & 0.9244 & 1.0000 & 0.4972 & 0.5844 \\
\hline$\beta$ & -0.4810 & 0.6400 & 0.4972 & 1.0000 & 0.7428 \\
\hline $\mathrm{D} \beta$ & -0.3175 & 0.5556 & 0.5844 & 0.7428 & 1.0000 \\
\hline \multicolumn{6}{|c|}{ Frontier Countries } \\
\hline Measures & M.R. & S.D & SE.D. & $\beta$ & $\mathrm{D} \beta$ \\
\hline M.R. & 1.0000 & -0.3004 & -0.3675 & 0.2250 & -0.4462 \\
\hline S.D & -0.3004 & 1.0000 & 0.9494 & 0.4249 & 0.7209 \\
\hline SE.D. & -0.3675 & 0.9494 & 1.0000 & 0.2712 & 0.8095 \\
\hline$\beta$ & 0.2250 & 0.4249 & 0.2712 & 1.0000 & 0.3987 \\
\hline $\mathrm{D} \beta$ & -0.4462 & 0.7209 & 0.8095 & 0.3987 & 1.0000 \\
\hline \multicolumn{6}{|c|}{ Combined Market Groups } \\
\hline Measures & M.R. & S.D & SE.D. & $\beta$ & $\mathrm{D} \beta$ \\
\hline M.R. & 1.0000 & -0.5837 & -0.6001 & -0.0651 & -0.3243 \\
\hline S.D & -0.5837 & 1.0000 & 0.9388 & 0.3589 & 0.5221 \\
\hline SE.D. & -0.6001 & 0.9388 & 1.0000 & 0.2628 & 0.6023 \\
\hline$\beta$ & -0.0651 & 0.3589 & 0.2628 & 1.0000 & 0.6183 \\
\hline $\mathrm{D} \beta$ & -0.3243 & 0.5221 & 0.6023 & 0.6183 & 1.0000 \\
\hline
\end{tabular}




\subsection{Regression Analysis}

We re-check the risk-return relationship by regressing country returns on MSCI ALL Country World Index returns separately for the two sub periods. The regression results are provided in Table 4. In sub period 1, we find insignificant negative risk-return relationship for developed and emerging markets, while for frontier markets, the relationship is observed to be negative but significant for alternative risk measures. In the post crisis period, we find that relationship between return and risk measures for developed markets remains negative for all risk measures; however, it becomes significant for standard deviation measures. In case of emerging markets also relationship is negative and significant for all risk measures except downside beta. The interesting observation with regards to frontier markets is that contrary to other market groups, the risk return relationship becomes insignificant, though negative, in post crisis period. On overall basis the risk-return relationship is absent in sub period 1 while it is significantly negative for standard deviation measures in the post crisis period. Unlike Estrada [5], we avoid estimating multi-variate regressions involving alternative risk measures as explanatory variables, given the high empirically observed correlations between these risk measures.

In sum, the risk-return relationship breaks down prior to the crisis period including the crisis phase. Hence, the verification of risk-return relationship can possibly provide us an early warning about the forthcoming crisis. The verification of risk-return relationship may be much easier than computing complex systemic risk measures (see Acharya et al. [17], Chan-Lau et al. [18], Adrian and Brunnermeier [19], WeiB et al. [20]) which are currently in vogue for crisis predictions. Further, alternative systemic risk measures may provide very different risk assessments ${ }^{3}$ for a given financial system incorporating a set of financial institutions. The post crisis negative risk-return relationship implies that world capital markets are not out of woods even till 2016. Thus, from the market perspective the impact of GFC is still being felt, even though economists may have a different view about economic recovery based on macro-economic data. The negative risk-return relationship reported for global financial markets imply that these markets exhibit an option like behavior around the crisis phase as well as the post crisis period. Risk seems to be an ally and, hence, has a favorable impact for corporate valuation which is in contrast to the implications of DCF models. The option like behavior is on account of the fact that these economies are "relatively distressed" in and around the post crisis period owing to declining GDP, shrinking world trade and rising debt to GDP ratios. The expected GDP and total economic debt may mimic spot price and exercise price respectively in ${ }^{3}$ Prior research compares four commonly used systemic risk metrics using data on U.S. financial institutions over the period 2005-2014. Four systemic risk measures are commonly used in empirical literature, 1) marginal expected shortfall, 2) codependence risk, 3) delta conditional value at risk, and 4) lower tail dependence. The alternative measurement approaches produce very different estimates of systemic risk. Further, Kleinowa et al. [24] show that the different systemic risk measures may lead to contradicting assessments about the riskiness of different types of financial institutions and hence their results should be interpreted cautiously. 
Table 4. Tests of risk-return relationships using regression analysis in and around the global financial crisis period. We provide the regression results of global financial crisis for three market groups separately for Pre as well as Post Crisis Periods. The S.D., SE.D., $\beta$ and $\mathrm{D} \beta$ stand for four risk measures namely, standard deviation, semi-deviation, beta and downside beta respectively.

\begin{tabular}{|c|c|c|c|c|c|c|c|c|c|c|}
\hline \multicolumn{11}{|c|}{ Panel A: Pre-Crisis Regressions } \\
\hline \multicolumn{11}{|c|}{ Developed Countries } \\
\hline$a$ & S.D. & SE.D & $\beta$ & $\mathrm{D} \beta$ & $t_{\alpha}$ & $t_{S . D .}$ & $t_{S E . D}$ & $i_{\beta}$ & $t_{D \beta}$ & adj $R^{2}$ \\
\hline 0.0080 & -0.0456 & & & & 1.5454 & -0.5972 & & & & 0.0114 \\
\hline 0.0107 & & -0.1022 & & & 1.9036 & & -1.0441 & & & 0.0465 \\
\hline 0.0109 & & & -0.0054 & & 3.0953 & & & -1.6918 & & 0.0557 \\
\hline 0.0097 & & & & -0.0043 & 2.5022 & & & & -1.2115 & 0.0420 \\
\hline \multicolumn{11}{|c|}{ Emerging Countries } \\
\hline$a$ & S.D. & SE.D & $\beta$ & $\mathrm{D} \beta$ & $t_{\alpha}$ & $t_{\text {S.D. }}$ & $t_{S E . D}$ & $t_{\beta}$ & $t_{D \beta}$ & adj $\mathbf{R}^{2}$ \\
\hline 0.0158 & -0.0052 & & & & 2.3011 & -0.0614 & & & & 0.0001 \\
\hline 0.0118 & & 0.0500 & & & 1.5980 & & 0.4090 & & & 0.0059 \\
\hline 0.0191 & & & -0.0029 & & 2.7616 & & & -0.5156 & & 0.0114 \\
\hline 0.0236 & & & & -0.0061 & 3.1696 & & & & -1.0867 & 0.0554 \\
\hline \multicolumn{11}{|c|}{ Frontier Countries } \\
\hline$a$ & S.D. & SE.D & $\beta$ & $\mathrm{D} \beta$ & $t_{\alpha}$ & $t_{S . D .}$ & $t_{S E . D}$ & $t_{\beta}$ & $t_{D \beta}$ & $\operatorname{adj} R^{2}$ \\
\hline 0.0283 & -0.1836 & & & & 4.7573 & -3.7896 & & & & 0.2959 \\
\hline 0.0269 & & -0.2323 & & & 8.3080 & & -6.9863 & & & 0.5078 \\
\hline 0.0167 & & & -0.0096 & & 3.7971 & & & -2.0629 & & 0.2495 \\
\hline 0.0145 & & & & -0.0064 & 2.6497 & & & & -1.8454 & 0.2051 \\
\hline \multicolumn{11}{|c|}{ Combine Market Groups } \\
\hline$\alpha$ & S.D. & SE.D & $\beta$ & $\mathrm{D} \beta$ & $t_{\alpha}$ & $t_{S . D .}$ & $t_{S E . D}$ & $t_{\beta}$ & $t_{D \beta}$ & $\operatorname{adj} R^{2}$ \\
\hline 0.0128 & -0.0366 & & & & 2.1895 & -0.5623 & & & & 0.0105 \\
\hline 0.0174 & & -0.1151 & & & 3.5054 & & -1.6481 & & & 0.0738 \\
\hline 0.0136 & & & -0.0034 & & 3.6907 & & & -1.1307 & & 0.0206 \\
\hline 0.0146 & & & & -0.0041 & 3.9532 & & & & -1.5597 & 0.0431 \\
\hline \multicolumn{11}{|c|}{ Panel B: Post-Crisis Regressions } \\
\hline \multicolumn{11}{|c|}{ Developed Countries } \\
\hline$\alpha$ & S.D. & SE.D & $\beta$ & $\mathrm{D} \beta$ & $t_{\alpha}$ & $t_{\text {S.D. }}$ & $t_{S E . D}$ & $t_{\beta}$ & $t_{D \beta}$ & $\operatorname{adj} R^{2}$ \\
\hline 0.0103 & -0.1490 & & & & 2.8858 & -2.0140 & & & & 0.1270 \\
\hline 0.0139 & & -0.3314 & & & 5.2433 & & -4.3647 & & & 0.3179 \\
\hline 0.0041 & & & -0.0015 & & 2.7102 & & & -1.0086 & & 0.0163 \\
\hline 0.0057 & & & & -0.0030 & 2.3405 & & & & -1.3527 & 0.0844 \\
\hline \multicolumn{11}{|c|}{ Emerging Countries } \\
\hline$\alpha$ & S.D. & SE.D & $\beta$ & $\mathrm{D} \beta$ & $t_{\alpha}$ & $t_{S . D .}$ & $t_{S E . D}$ & $t_{\beta}$ & $t_{D \beta}$ & $\operatorname{adj} R^{2}$ \\
\hline 0.0115 & -0.2187 & & & & 3.7967 & -5.6273 & & & & 0.4617 \\
\hline 0.0095 & & -0.3001 & & & 3.6655 & & -6.2994 & & & 0.4112 \\
\hline 0.0053 & & & -0.0085 & & 2.0733 & & & -3.2950 & & 0.2313 \\
\hline 0.0007 & & & & -0.0041 & 0.1915 & & & & -1.2260 & 0.1008 \\
\hline
\end{tabular}




\section{Continued}

\begin{tabular}{|c|c|c|c|c|c|c|c|c|c|c|}
\hline \multicolumn{11}{|c|}{ Frontier Countries } \\
\hline$\alpha$ & S.D. & SE.D & $\beta$ & $\mathrm{D} \beta$ & $t_{\alpha}$ & $t_{S . D .}$ & $t_{S E . D}$ & $t_{\beta}$ & $t_{D \beta}$ & $\operatorname{adj} R^{2}$ \\
\hline 0.0045 & -0.1092 & & & & 0.4744 & -0.7044 & & & & 0.0903 \\
\hline 0.0053 & & -0.1865 & & & 0.6242 & & -0.8587 & & & 0.1350 \\
\hline-0.0062 & & & 0.0041 & & -1.7783 & & & 1.4544 & & 0.0506 \\
\hline 0.0015 & & & & -0.0054 & 0.5103 & & & & -1.1270 & 0.1991 \\
\hline \multicolumn{11}{|c|}{ Combine Market Groups } \\
\hline$a$ & S.D. & SE.D & $\beta$ & $\mathrm{D} \beta$ & $t_{\alpha}$ & $t_{S . D .}$ & $t_{S E . D}$ & $t_{\beta}$ & $t_{D \beta}$ & $\operatorname{adj} R^{2}$ \\
\hline 0.0116 & -0.2018 & & & & 3.2346 & -3.2924 & & & & 0.3407 \\
\hline 0.0113 & & -0.3063 & & & 3.5009 & & -3.7100 & & & 0.3601 \\
\hline-0.0003 & & & -0.0011 & & -0.1169 & & & -0.4803 & & 0.0042 \\
\hline 0.0032 & & & & -0.0043 & 1.4218 & & & & -1.8806 & 0.1052 \\
\hline
\end{tabular}

the real option framework. Market groups with rising debt to GDP ratios are likely to be more distressed and hence should exhibit stronger option like behavior.

This can be clearly seen for developed market group where the average public debt to GDP ratio rose from $51 \%$ to $70 \%$ from pre to post crisis period, with 9 out of 21 countries reporting Debt to GDP ratio greater than $90 \%$ in 2015 (see exhibit 1). Hence, these markets behave more option like and continue to provide better valuations (owing to positive returns) consistent with the Option Greek named as Vega. In contrast, the average public debt to GDP ratio for emerging and frontier markets do not change significantly from pre to post crisis period. Thus, these markets are relatively less distressed. The general decline in GDP, however, stresses all economies. Figure 1 shows the average public debt to GDP ratios for the three market groups.

We recommend that corporate valuations in an around crisis periods (including GFC) must be performed using contingent claims approach instead of standard DCF models. Further the cost of equity estimation using CAPM and other standard asset pricing models makes no sense when the risk-return relationship is empirically negative. Instead the cost of equity should be estimated from the option pricing model by incorporating a risk premium over and above the benchmark risk free rate. Such a risk premia should be a function of the probability of economic default, that is, what is the possibility that a country's GDP is sufficient to honor its public debt. Our findings are strong and have implications for forecasting economic crisis and warrant a re-examination of current asset pricing and cost of equity estimation frameworks beyond the tranquil periods.

However, our conclusions run the risk of being event specific i.e. ensuing to GFC. We are, therefore, motivated to choose another crisis phase in global financial markets. We select the Asian Crisis which started from July 1997 and ended in December 1998. 


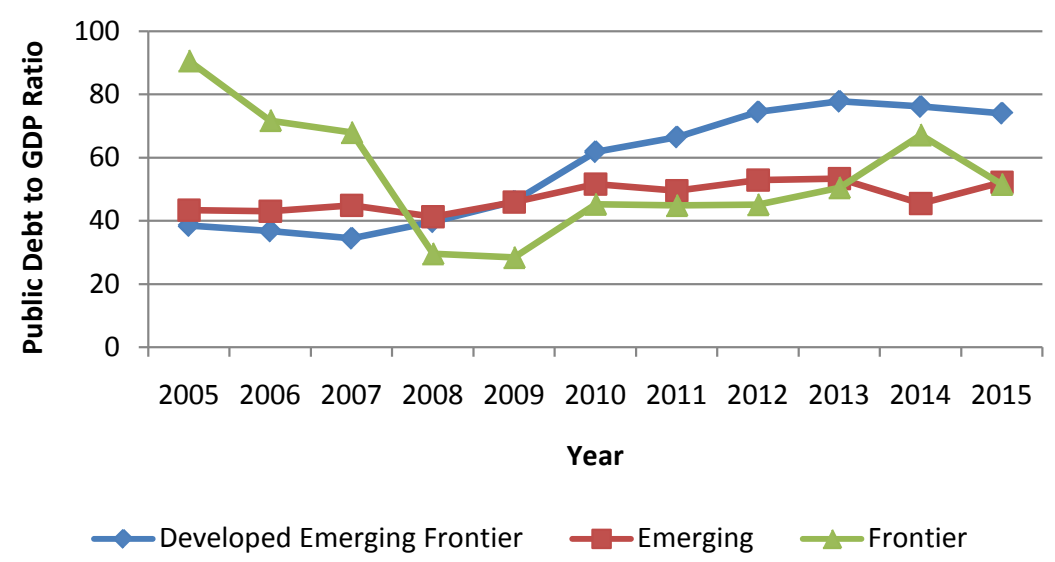

Figure 1. Average Debt to GDP Ratio from 2005 to 2015.

\subsection{Risk -Return Relationships in and Around Asian Debt Crisis}

In order to check for the robustness of our results, we test the risk-return relationship using the regression analysis separately for sub period 1 and 2 for Asian crisis of 1997. The first sub period named as the pre-crisis period (including crisis months) is from June 2005 to December 2010 and second sub period called as post crisis period is from June 1994 to June 2003. We report the regression results in two parts. In part one we report the results only for Asian economies which belong to the sample used for GFC crisis and which were directly impacted by the Asian crisis. We use data for 12 out of 14 sample Asian countries as sufficient historical market index information is not available for Bangladesh and Vietnam in Bloomberg. In part two, we report regression results using 40 sample markets, including the Non-Asian markets, as these markets may be highly linked to Asian economies owing to international trade and investment flows. 14 countries have been excluded in this phase due to lack of data. The results for Asian economies as well as all economies in and around the Asian Crisis are almost similar. The risk-return relationship is significantly negative using the standard deviation based measures in the sub period 1 while they are significantly positive in the post crisis period. Significant risk return relationship is, however, generally absent both for pre and post Asian crisis periods using beta based measures. These results are reported in Table 5. In other words the risk-return relationship as confirmed by standard asset pricing models like CAPM breaks down in and around the crisis period, thus reconfirming the power of these simple tests in diagnosing crisis. The world economies seem to recover quickly from the Asian crisis as compared to GFC given the regional nature of economic stress which did not have long reaching implications for most global financial markets.

Thus, by taking an out of the sample study for an alternative crisis period, we show that by verifying a simple risk-return relationship, using bivariate regressions, one can get an indication about a prospective financial crisis. Hence, an absence of risk-return relationship may be a good indicator of global economic health rather than using more computationally expensive econometric 
Table 5. Tests of risk-return relationships using regression analysis in and around the Asian crisis period. The table provides the regression results using the alternative risk measures for Asian Financial Crisis divided into four panels. The first two panels include the results of pre and post crisis period for the 12 Asian countries while the last two panels provide results of pre and post crisis period for all the countries (which includes 40 countries out of the total 54 selected for global financial crisis).

\begin{tabular}{|c|c|c|c|c|c|}
\hline \multicolumn{6}{|c|}{ Panel A: Regression Results for Asian Countries in the pre-crisis period } \\
\hline Risk Measures & $a$ & $\beta$ & $T a$ & $T \beta$ & $\operatorname{adj} R^{2}$ \\
\hline STANDARD DEVIATION & 0.011214 & -0.18674 & 3.754142 & -8.588952 & 0.620462 \\
\hline SEMI DEVIATION & 0.014318 & -0.37306 & 2.177309 & -3.792264 & 0.52203 \\
\hline BETA & 0.003527 & -0.01042 & 0.387055 & -1.796976 & 0.326228 \\
\hline DOWNSIDE BETA & -0.00942 & -0.00176 & -1.39034 & -0.577129 & 0.005239 \\
\hline \multicolumn{6}{|c|}{ Panel B: Regression Results for Asian Countries in the post-crisis period } \\
\hline Risk Measures & $a$ & $\beta$ & $T a$ & $T \beta$ & $\operatorname{adj} R^{2}$ \\
\hline STANDARD DEVIATION & -0.01459 & 0.211873 & -2.97844 & 4.544677 & 0.445835 \\
\hline SEMI DEVIATION & -0.00832 & 0.305856 & -1.30098 & 2.926435 & 0.253045 \\
\hline BETA & 0.012623 & -0.00544 & 2.085807 & -0.862092 & 0.070011 \\
\hline DOWNSIDE BETA & 0.009109 & -0.00185 & 1.733238 & -0.335391 & 0.009437 \\
\hline \multicolumn{6}{|c|}{ Panel C: Regression Results for All Countries in the pre-crisis period } \\
\hline Risk Measures & $\alpha$ & $\beta$ & $T a$ & $T \beta$ & adj $R^{2}$ \\
\hline STANDARD DEVIATION & 0.019909 & -0.19077 & 4.118235 & -3.514938 & 0.268187 \\
\hline SEMI DEVIATION & 0.019858 & -0.29658 & 2.816259 & -2.401454 & 0.20349 \\
\hline BETA & 0.012685 & -0.00862 & 1.712115 & -1.357332 & 0.089825 \\
\hline DOWNSIDE BETA & -0.00554 & 0.005533 & -0.67448 & 1.16733 & 0.050227 \\
\hline \multicolumn{6}{|c|}{ Panel D: Regression Results for All Countries in the post-crisis period } \\
\hline Risk Measures & $a$ & $\beta$ & $T a$ & $T \beta$ & $\operatorname{adj} R^{2}$ \\
\hline STANDARD DEVIATION & -0.01065 & 0.147381 & -4.79393 & 5.688466 & 0.347052 \\
\hline SEMI DEVIATION & -0.00973 & 0.24624 & -4.24449 & 6.113023 & 0.230518 \\
\hline BETA & 0.001137 & 0.006395 & 0.88681 & 3.111262 & 0.142147 \\
\hline DOWNSIDE BETA & 0.001007 & 0.002079 & 0.285007 & 0.64411 & 0.021579 \\
\hline
\end{tabular}

modelling employing complex macro potential risk measures. Further, option pricing models seem to be more relevant for corporate valuation and cost of equity estimations in and around the crisis periods. The virtual absence of risk return-relationship for large part of global stock market history over the last 22 years casts a shadow on CAPM and other standard asset pricing models which have assumed to be a gospel truth in the world of investment valuation.

\section{Summary and Conclusion}

The risk and return relationship has been a prominent subject of research in contemporary finance and there have been divergent findings with regards to the direction of this relationship. The seminal research work of Sharpe [1] has established a positive relationship between the two parameters, more popularly 
known as CAPM; however, there have been empirical evidences which show a negative risk-return relationship. The two approaches to equity valuation, mainly the DCF model and contingent claim approach, assume contradictory relationships between risk, return and valuation. In the world of DCF, risk being the discounting factor is an adversary whereas in contingent claim valuation risk is an ally for valuation, because as volatility increases, equity value also increases. During the crisis periods, economies become relatively distress and in such circumstances contingent claim approach may be more relevant to value such economies. The existing literature has suggested either the best method of finding out cost of equity for various markets or established a positive or negative risk return relationship using linear or non-linear and static versus dynamic models. However, the literature is almost absent dealing while with risk-return relationship around the crisis periods.

In order to empirically verify the risk-return relationship during crisis period, we conduct the present study for Global Financial Crisis of 2008 with the following objectives: to test the risk-return relationship in pre-global financial crisis period for different types of markets; to evaluate the risk-return relationship for the post crisis period; to check the robustness of risk-return relationships using alternative risk measures; to test if pre crisis risk-return relationship patterns can be used for predicting crisis; to draw implications for corporate valuations and cost of equity estimation in the post crisis period.

Sample of 54 Morgan Stanley Capital Indices (MSCI) equity market indices is divided into three market groups, comprising of 21 Developed, 22 Emerging and 11 Frontier countries, and MSCI ALL Country World Index, representing global market index, has been taken from Bloomberg to conduct the study. The period under study has been taken from June 2005 to June 2016 which has been divided into two equal halves of 5 and half years each to perform pre- and post-crisis analysis.

We investigate the risk-return relationship by taking four measures of risk viz. standard deviation, semi-deviation, beta and downside beta. We find that the associations between returns within different market groups have weakened from sub period 1 to sub period 2. We further find the negative correlations between risk and return among the three market groups because both the sub periods and the results are similar for alternative risk measures. We also, observe that many risk measures are highly correlated to each other in both the sub periods, although this relationship sobers down in sub period 2. Therefore, the choice of risk measure should not significantly impact our asset pricing analysis.

Finally, we re-check the risk-return relationship by regressing country returns on MSCI ALL Country World Index returns separately for the two sub periods. We report either the absence or negative relationship between risk and return for the three market groups taken separately. On overall basis, the risk-return relationship is absent prior to the crisis period including the crisis phase while it is found to be negative in the post crisis period, thus implying that the shadow of GFC still looms large on global financial markets. Hence, the verification of 
risk-return relationship can possibly provide us an early warning about the forthcoming crisis. The absence of risk-return relationship using two parameter asset pricing model may be much easier to estimate than complex systemic risk measures, which are computationally expensive but currently in vogue, which are generally recommended for crisis forecasting. The negative risk-return relationship reported for global financial markets imply that these markets exhibit an option like behavior around the crisis phase as well as the post crisis period. The option like behavior is on account of the fact that these economies are "relatively distressed" in and around the post crisis period owing to declining GDP, shrinking world trade and rising public debt to GDP ratios.

We recommend that corporate valuations in an around GFC must be performed using contingent claims approach instead of standard DCF models. Further, the cost of equity estimation using CAPM and other standard asset pricing models makes no sense when the risk-return relationship is empirically negative. Instead the cost of equity should be estimated from the option pricing model by incorporating a risk premium over and above the benchmark risk free rate. Such a risk premium should be a function of the probability of economic default that is what is the possibility that a country's GDP is not sufficient to honor its public debt. Our findings have strong implications for forecasting economic crisis and warrant a re-examination of current asset pricing and cost of equity estimation frameworks beyond the tranquil periods.

In order to check for the robustness of our results, we re-test the risk-return relationship for the Asian crisis of 1997 for the period from June 1994 to June 2003 divided into two equal periods of 4 and a half years each for our analysis. In conformity to our findings for GFC, we find absence of risk-return relationship prior to crisis period. Thus, we infer that examination of the risk-return relationship and confirmation of its absence may be an early warning system for diagnosing possible financial crisis.

Our results have implications for asset pricing, portfolio construction and valuations. It can be clearly seen in our study that over the last 22 years about $80 \%$ of the time period, risk-return relationship does not confirm to the standard asset pricing framework. The findings raise serious questions about the applicability of CAPM and other asset pricing models and their further use for corporate valuations, cost of equity estimations and market efficiency inferences. Further, the declining return correlations overtime across all market groups have positive implications for portfolio diversification within the Markowitz framework. Tests of risk-return relationship may be a simpler approach for crisis prediction than use of Complex Systemic risk measures (S risk measures) which are computationally expensive. The absence of risk-return relationship seems to be a good predictor of forthcoming financial crisis. For corporate practitioners as well as academic point of view, contingent claim approach to equity valuation seems to be more appropriate compared to standard DCF models in and around the crisis period. The cost of equity also needs to be measured using option 
pricing framework as negative risk-return relationship may lead to misleading estimations. The study provides insights into the working of global financial markets and how these markets evolve (or fail to evolve) risk-return relationship consistent with standard asset pricing framework. The study contributes to capital market literature with special emphasis on the crisis period.

\section{References}

[1] Sharpe, W. (1964) Capital Asset Prices: A Theory of Market Equilibrium under Conditions of Risk. The Journal of Finance, 19, 425-442.

[2] Lintner, J. (1965) The Valuation of Risk Assets and the Selection of Risky Investments in Stock Portfolios and Capital Budgets. The Review of Economics and Statistics, 47, 13-37. https://doi.org/10.2307/1924119

[3] Mossin, J. (1966) Equilibrium in a Capital Asset Market. Econometrica, 34, 768-783. https://doi.org/10.2307/1910098

[4] Estrada, J. (2000) The Cost of Equity in Emerging Markets: A Downside Risk Approach. Emerging Markets Quarterly, 4, 19-30.

[5] Estrada, J. (2007) Mean-Semivariance Behavior: Downside Risk and Capital Asset Pricing. International Review of Economics and Finance, 16, 169-185. https://doi.org/10.1016/j.iref.2005.03.003

[6] Collins, D. (2003) Measuring the Cost of Equity in Frontier Financial Markets. University of Cape Town, Cape Town.

[7] Abrahamason, D.C. (2005) Measuring the Cost of Equity in African Financial Markets. Emerging Market Review, 7, 67-81.

[8] Zhi Da, R.-Z.G. (2012) CAPM for Estimating the Cost of Equity Capital: Interpreting the Empirical Evidence. Journal of Financial Economics, 103, 204-220. https://doi.org/10.1016/j.jfineco.2011.08.011

[9] Hasan, M.M., Hossain, M., Cheung, A. and Habib, A. (2015) Corporate Life Cycle and Cost of Equity Capital. Journal of Contemporary Accounting \& Economics, 11, 46-60. https://doi.org/10.1016/j.jcae.2014.12.002

[10] Menachem Abudy, S.B. (2016) The Cost of Equity for Private Firms. Journal of Corporate Finance, 37, 431-443. https://doi.org/10.1016/j.jcorpfin.2016.01.014

[11] Salvador, F.A. (2014) Re-Examining the Risk-Return Relationship in Europe: Linear or Non-Linear Trade-Off? Journal of Empirical Finance, 28, 60-77. https://doi.org/10.1016/j.jempfin.2014.05.004

[12] Chiang, L.Z. (2015) The Intertemporal Risk-Return Relationship: Evidence from International Markets. Journal of International Financial Markets, Institutions and Money, 39, 156-180. https://doi.org/10.1016/j.intfin.2015.06.003

[13] Aslanidis, C. (2016) Risk-Return Trade-Off for European Stock Markets. International Review of Financial Analysis, 46, 84-103. https://doi.org/10.1016/j.irfa.2016.03.018

[14] Khan, Z.W. (2016) Market States and the Risk-Return Tradeoff. The Quarterly Review of Economics and Finance, 65, 314-327.

[15] Liu, M. (2017) Cross-Sectional Determinants of Information Quality Proxies and Cost of Capital Measures. Quarterly Journal of Finance, 7, Article ID: 1650016. https://doi.org/10.1142/S2010139216500166

[16] Estrada, J. (2004) The Cost of Equity of Internet Stocks: A Downside Risk Ap- 
proach. The European Journal of Finance, 10, 239-254.

https://doi.org/10.1080/1351847032000137429

[17] Acharya, V., Engle, R. and Richardson, M. (2012) Capital Shortfall: A New Approach to Ranking and Regulating Systemic Risks. American Economic Review, 102, 59-64. https://doi.org/10.1257/aer.102.3.59

[18] Chan-Lau, J.A., Espinosa, M., Giesecke, K. and Sole, J.A. (2009) Assessing the Systemic Implications of Financial Linkages. IMF Global Financial Stability Report, 2, 73-110.

[19] Adrian, T. and Brunnermeier, M. (2016) CoVaR. American Economic Review, 106, 1705-1741. https://doi.org/10.1257/aer.20120555

[20] WeiB, G.N., Neumann, S. and Bostandzic, D. (2014) Systemic Risk and Bank Consolidation: International Evidence. Journal of Banking \& Finance, 40, 165-181. https://doi.org/10.1016/j.jbankfin.2013.11.032

[21] Trichet, J.-C. (2010) State of the Union: The Financial Crisis and the ECB's Response Between 2007 and 2009. Journal of Common Market Studies, 48, 7-19.

[22] Angelini, P., Nobili, A. and Picillo, C. (2011) The Interbank Market after August 2007: What Has Changed, and Why? Journal of Money, Credit and Banking, 43, 923-958.

[23] Sehgal, S., Gupta, P. and Deisting, F. (2017) Assessing Time-Varying Stock Market Integration in Economic and Monetary Union for Normal and Crisis Periods. European Journal of Finance, 23, 1025-1058.

[24] Kleinow, J., Moreira, F., Strobl, S. and Vahamaa, S. (2017) Measuring Systemic Risk: A Comparison of Alternative Market Based Approaches. Finance Research Letters, 21, 40-46. https://doi.org/10.1016/j.frl.2017.01.003 